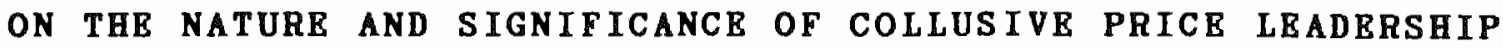

by

\title{
LEO SLEUWAEGEN
}

(INCAP - K.U. Leuven $)^{\circ}$

ABSTRACT

With the help of a simple analytical model we are able to analyze and to further clarify the conditions for collusive price leadership as they were originally devised by Jesse Markham. Within the confines of this model we show how collusion increases price cost margins, but at the same time decreases concentration in the industry.

INdustry and Company Analysis Program, University of Louvain. I am grateful to Raymond De Bondt, Denis de Crombrugghe, and two anonymous referees for suggestions which have considerably improved the exposition of the arguments in this paper. 
On the nature and significance of collusive price leadership

\section{Introduction}

The price leadership model has recently regained a renewal of interest among industrial economists. Research centers around the basic problem of who will adopt the positions of leaders and followers in the industry, and to what extent a cartel of price leaders will be stable (see, e.g. Ono (1978), Boyer and Moreaux (1982), d'Aspremont et al. (1983), Donsimoni and Mcleod (1984)). Also the dynamical implications of the model are the subject of intense debate (Geroski and Jacquemin (1984)). However, these studies did not always produce unequivocal results. Much of the controversy about some of the results seems to depend on the particular assumptions made about the behaviour of firms within the industry. In this connection the ongoing debates focusing on collusive price leadership sometimes overlook some of the basic conditions characterizing the emergence of this type of market arrangement, as they were originally devised by Jesse Markham (1951).

The aim of this paper is to exposit some arguments which illustrate the importance of Markham's original conditions. We consider this analysis necessary, because the importance of these conditions seems not to have been fully appreciated 
in subsequent research, as revealed by some of the comments responding to Markham's original article (e.g. Oxtenfeldt (1952), Lanzilotti (1957)).

In section 2 of the paper we show the effect of enforcing collusion among the leading firms in the industry on the degree of monopoly power in the industry. The relationship implies a combined effect of two different concentration measures, the concentration ratio ( $C_{k}, k$ being the number of dominant firms) and the Hirschman-Herfindahl (H) index. We show that the explicit distinction between these two different concentration measures is not trivial, but becomes crucially important for highly concentrated industries where few large firms dominate the industry. In section 3 we analyze how concentration may create incentives to collude. However, concentration, as a structural quantity measure, is no exogenous determinant of performance. In section 4 we show how concentration is endogenously determined by oligopolistic conduct within the industry. By numerically solving the model we then illustrate how strict enforcing of collusion among the members of the dominant cartel will entail higher profits with lower concentration in the industry . 
2. Imperfect collusion in price leadership oligopoly.

In the new view on the relationship between market structure and performance oligopolistic conduct plays a predominant role. However, in spite of the recognition of the importance of conduct, very few studies have analyzed the behavioural motivations of the firms within the industry. A well known and early exception to this observation is stigler (1964) who asserted that oligopolists are profit maximizers and, consequently, will prefer the collusive solution above all others. However, because of the tendency of individual firms to 'chisel', i.e. to engage in secret price cutting in order to increase individual market shares and profits, the actual outcome in the market may be different from the collusive equilibrium. In stigler's view the problem of enforcing the joint profit maximizing solution is thus considered to be an information (detection) problem. Based upon this view, John Cubbin (1982) related the set of stable industry price-cost margins to the degree of imperfection of collusion, measured in terms of reaction probabilities or retaliation lags reflecting information defects.

Although the model has more relevance for product-differentiated industries, it is interesting to apply Cubbin's model to the collusive price-leadership model. Particularly, this approach enables us to illustrate the importance of the five conditions for the occurence of this type of oligopoly, as they where originally devised by Jesse Markham. Apparently, 
because of the lack of analytical tools, the importance of some of the conditions seemed not to have been fully appreciated by those who commented upon their relevance.

To show this, assume that there are $n$ firms and that the $k$ largest dominate the industry. Denoting quantity by $q$ and price by $p, q=F(p)$ represents the global demand function to the industry, and $q c=G(p)$ the supply function of the competitive fringe. The demand function facing the dominant group can then be written as $q D=q-q C=F(p)-G(p)$. Next define the quantities - $[\mathrm{dF}(\mathrm{p}) / \mathrm{dp}][\mathrm{p} / \mathrm{F}(\mathrm{p})]=\mu$ and $[p / G(p)][d G(p) / d p]=\epsilon$ as respectively the absolute value of elasticity of industry demand and the elasticity of supply of the competitive fringe.

Under these conditions it follows that the elasticity of demand for the $k$ largest (dominant) firms equals (see Saving $(1970)):$

$$
\mu_{D}=\frac{1}{C_{k}}\left(\mu+\left(1-C_{k}\right) \epsilon\right)
$$

In line with Cubbin's analysis, we now assume that all leading firms believe that they can increase their profits by lowering their price (increasing the quantity sold), and expect that with a certain probability $\alpha$ others will not react by retaliatory price reductions. The resulting (leading firm's) price-cost margin will equal a weighted 
combination of the (noncooperative) cournot and perfect collusive outcome with $\alpha$ as the weight factor:

$$
\lambda_{i}=\frac{1}{\mu_{D}}\left[\alpha+(1-\alpha) s_{D i}\right] \quad i=7, \ldots, k
$$

where $S_{D i}=q_{i} / Q_{D}$, firm i's share of the quantity sold by the dominant group

Result (2) can also be obtained from a conjectural variation model (see Clark and Davies (1982)). Without discussing these different approaches here, the essence of $\alpha$ in the model lays in its role as characterising the degree of (apparent or implicit) collusion in the industry.

Since the $n-k$ remaining firms of the competitive fringe act as price-takers their corresponding Lerner index necessarily equals zero, or $\lambda_{i}=0 ; i=k+1, \ldots, n$. By weighting the Lerner index for the $k$ dominant firms and the $n-k$ remaining firms with their respective market shares we obtain the following measure of monopoly power for the industry:

$$
\lambda=\sum_{i=1}^{n} s_{i} \lambda_{i}=\frac{\alpha C_{k}{ }^{2}+(1-\alpha) H_{k}}{\mu+\epsilon\left(1-C_{k}\right)}
$$

where $H_{k}=\sum_{i=1}^{k} s_{i} 2$ the truncated (leading firm component of the) Hirschman-Herfindahl index. If (as Hause (1977) did) one assumes competitive fringe firms to be very small, $H_{k}$ 
approximately equals $H=\sum_{i=1}^{n} s_{i}{ }^{2}$ the ordinary HirschmanHerfindahl index. Below we shall discuss this in more detail.

It can easily be seen from relation (3) that with $\alpha=1$ Saving's collusive result holds, and with $\alpha=0$ Hause (1977), Encaoua and Jacquemin's (1980) non-collusive (Cournot) result holds. With $0<\alpha<1$, we have a partially collusive equilibrium, which amounts to a weighted average of the two extreme solutions. Moreover, for $C_{k}$ approaching one, relation (3) reduces to the basic (no competitive fringe) oligopoly model (see Cubbin (1983)).

With respect to the discussion which of the two concentration measures, $\mathrm{H}$ (approximating $\mathrm{H}_{k}$ for $\mathrm{k}<\mathrm{n}$ ) or $\mathrm{C}_{\mathrm{k}}$ squared, is more appropriate to explain price-cost margins, we find that relation (3) provides a more flexible specification, involving a weighted combination of both measures, with $\alpha$ the empirically estimable weight.

Distinguishing the roles of the separate concentration measures is not trifling, as is sometimes suggested in the literature, but becomes crucially important to assess industry performance for these industries where the leading firms hold a large share of the market. The point is illustrated in Figure 1 for the four-firm concentration ratio. 
FIGURE 1 : THE HORN RELATIONSHIP BETWEEN C 4 AND H ILLUSTRATED WITH BELGIAN DATA (NACE-INDUSTRIES, 1981)

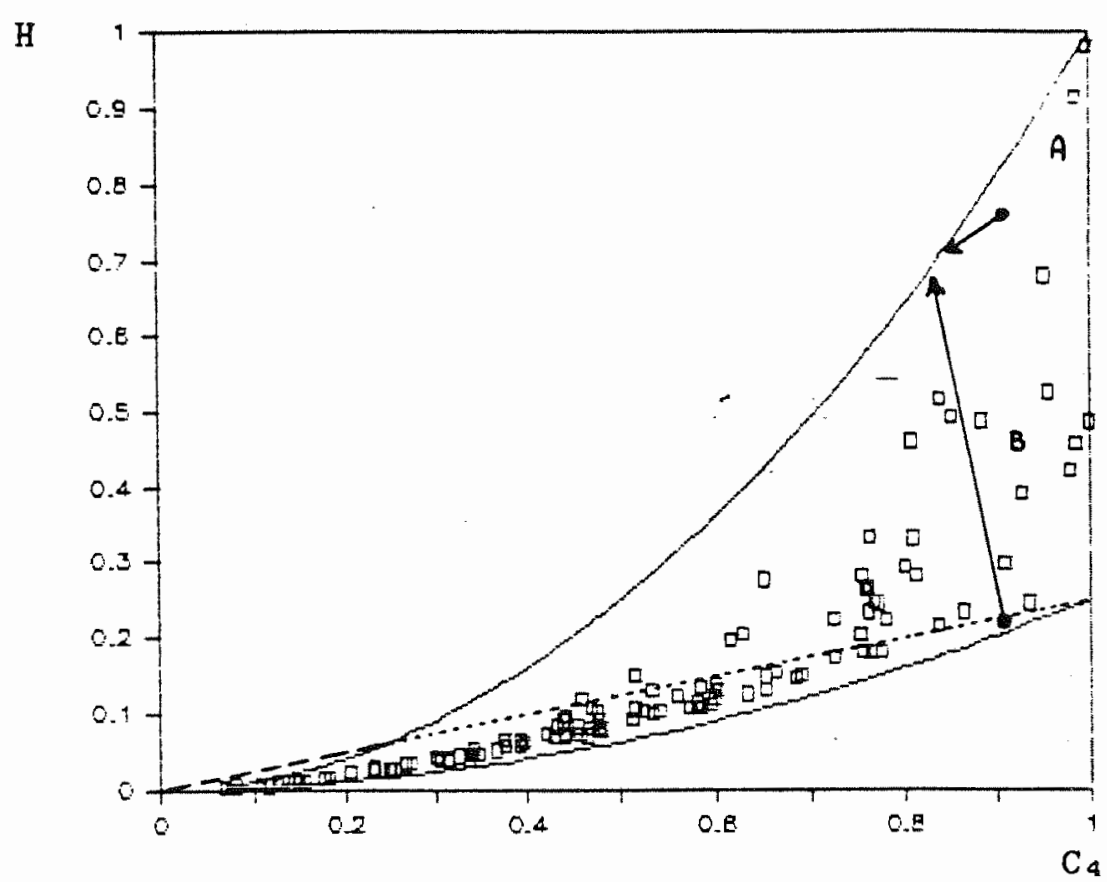

The figure shows the relationship between $H$ and $C_{4}$ in the shape of a horn (*). A "horn" relationship is not only valid for $C_{4}$, but applies to all $C_{k}$ measures, $k$ taking on different values. The arguments that follow also hold for $k$ different from 4. For $C_{4}>1 / 4$, the upper boundary equals $\mathrm{C}_{4}{ }^{2}$, which corresponds to the numerator of equation (3) for the collusive outcome with four leading firms. The upper boundary for $\mathrm{C}_{4}<1 / 4$, equals $\mathrm{C}_{4} / 4$ and can be interpreted as

(*) The derivation of the boundaries follows from the transfer principle, which the H-index satisfies, under the restriction of given $C_{k}$ values (see Sleuwaegen and Dehandschutter (1985)) 
a conditional (upon $C_{4}$ ) number equivalent $H$ value (see Adelman (1969)). Because of this relevance we have extended the line over the whole range of $\mathrm{C}_{4}$ values. The lower boundary of the horn is given by $\mathrm{C}_{4} 2 / 4$, or the $\mathrm{H}$ index when all 4 leading firms hold equal shares of the market. It should be noticed that both the upper boundary for $\mathrm{C}_{4} \geq$ $1 / 4$ ) and the lower boundary are the same for $\mathrm{H}_{4}$ and $\mathrm{H}$ since the maximum and minimum $H$ assume the contribution of the remaining $n-4$ firms to approach zero. For $C_{4}<1 / 4$ the upper boundary of $\mathrm{H}_{4}$ is $\mathrm{C}_{4}{ }^{2}$. Clearly, for the sample of Belgian industries displayed in figure $\mathrm{l}, \mathrm{C}_{4}$ and $\mathrm{H}$ are not in approximate linear relation to each other, and hence are not easily exchangeable as explanatory variables for pricé-cost margins.

3. Incentives to collude.

Recognizing that the effect of collusion on industry profitability depends on the oligopolistic structure of the industry this, however, involves only one prerequisite condition for collusive price leadership to emerge and to become effective. In an early contribution to the subject Jesse Markham (1951) devised five different conditions for collusive price leadership to come about (1951). These conditions are (i), the industry must be tightly oligopolistic, (ii) there must be effective barriers to entry in the 
industry, (iii) products are to be close substitutes, (iv) demand must be relatively inelastic and ( $v$ ) individual cost curves must be sufficiently similar.

In two important comments, oxtenfeld (1952) and Lanzillotti (1957) argued that these conditions are not straightforward to interpret. In the opinion of these authors, they are particularly restrictive and at the same time, incomplete in their capacity of defining a unique set of equilibrium conditions for collusive price-leadership.

However, without spelling out all the details of these criticisms, it seems to us that the commenters did not fully exploit Markham's arguments leading to 'the right interpretation of the term "prerequisite conditions". As the real source of collusive arrangement Markham emphasized the "identity between the long term interests of each individual firm and those of the industry as a whole". It is from this basic provision that the relevance of the five more specific conditions should be interpreted.

The congruence of the individual firm's interests with those of the industry will be closer the more concerted action in the industry does result in larger benefits. In Markham's argumentation, these potential profits constitute the highest incentive for firms to collude. Thus one should analyse the significance of the five conditions in their relationship with these potential profits. As we shall demonstrate, 
formula (3) together with Figure I provide two convenient tools to do so.

The denominator of formula (3) implies that industry profits will be larger the lower is industry demand elasticity (condition iv) and the higher are barriers to entry which limit the magnitude of the competitive fringe supply elasticity $\in$ (condition $i i$ ). Also the interpretation of condition (iii) poses no particular problems. When the firm's product is sufficiently differentiated from rivals, price interdependence is low and the firm shapes its own industry. The real controversy around Markham's conditions arose from conditions (i) and (v): the oligopolistic'structure and the similarity of the cost curves of the firms in the industry. Therefore, the analysis presented here may be most helpful with respect to these two conditions.

Figure (1) shows that for low levels of concentration, noncooperative (Cournot) behaviour corresponding to the $\mathrm{H}_{k}$ index, or collusive behaviour corresponding to $\mathrm{C}_{k}{ }^{2}$, makes little difference for industry performance. According to formula (3) it is only in the wide zones of the horn, for high $C_{k}$ values, that collusion can yield these high industry returns compared to cournot behaviour. The emphasis in the previous sentence is on "can" since the outcome is really dependent upon the different positions of the firms. If the shares of the large firms are very unequally distributed 
resulting in a high value of the $H_{k}$ index within the horn, Cournot or collusive behaviour would, following formula (3), make little difference in terms of industry returns. In some particular cases, most likely to occur in the very high concentration zones collusion may even decrease industry returns, provided that collusion makes the concentration ratio to decrease (as will be formally shown in the next paragraph).

From Figure (1) we can derive, however, that the phenomenon of negative collusion effects on industry price cost margins, is only likely to occur in these industries with high $H_{k}$ values for given $C_{k}$ values. This is illustrated with arrow $A$ (lowest $H_{k}=H$ index possible) and arrow $B$ (high $H_{k}$ index) indicating the possible effects of collusion. Case A implies a very large increase in industry profits while for case B, collusion would imply a decrease in industry profits which the dominant firm would never accept. As we shall formally show in the next section, the height of the $H_{k}$ index under cournot depends crucially upon the efficiency differentials among the $k$ firms. If industrial firms cost structures are similar the ( $\mathrm{C}_{k}$-conditional) $\mathrm{H}_{k}$ index will be low and potential industry collusion rewards high. Thus, as with the degree of concentration, the real meaning of Jesse Markham's original collusion condition of "sufficiently similar cost curves" is again analytically derivable from both figure (1) and formula (3). 
Formally, the effect of going from Cournot to collusion can be analyzed by differentiating ( 3 ) with respect to $\alpha$. This differentiation can be decomposed as follows

$$
\frac{\delta \lambda}{\delta \alpha}=\left.\frac{\delta \lambda}{\delta \alpha}\right|_{d s_{i}=0}+\left.\sum_{i=1}^{n} \frac{\delta \lambda}{\delta s_{i}}\right|_{d \alpha=0} \frac{\delta s_{i}}{\delta \alpha}
$$

As long as $\alpha$ the degree of collusion, would not affect the sizes of firms within the industry ( $\left.d s_{i}=0\right)$, the effect of increasing collusion would simply be:

$$
\frac{\delta \lambda}{\delta \alpha}=\frac{C_{k}{ }^{2}-H_{k}}{\mu+\epsilon\left(1-C_{k}\right)}>0
$$

However, since collusive behaviour implies price increases, and $\epsilon>0, C_{k} / \alpha$ is necessarily negative. To what extent $C_{k}$ and in what directions $H_{k}$ will move with collusion will of course depend on what firm will set which price. The final outcome of collusion on industry price cost margin will depend on these concentration effects.

It should be noticed here that the results do not oppose the concept of a critical concentrical ratio; i.e. the lowest possible concentration ratio inducing firms, (because of substantial possible profit gains) to collude.

However, instead of considering this critical ratio as a fixed magic number for all industries, it follows from the 
analysis that the existence and magnitude of such a ratio is dependent upon other structural conditions, such as cost structure differences among firms and, as will be discussed in the next section, the numbers of leading firms in the industry .

The increasing incentives to collude for larger values of $C_{k}$, causing $\alpha$ to depend positively upon this last variable, is consistent with some recent empirical findings (see Clarke, Davies and Waterson (1984)). However, to properly test our collusion hypothesis $\alpha$ should be related to the difference between $C_{k}{ }^{2}$ resulting from collusion and the $H$ under Cournot behaviour.

4. Industrial concentration under collusive price leadership oligopoly

As Clarke and Davies (1982) have shown for the basic oligopoly model, the price leadership oligopoly model discussed above implies a joint determination of both price-cost margin and concentration within the dominant group and the competitive fringe.

Following their analysis, but replacing $\mu$ by $\mu_{D}$ (the industry demand elasticity by the demand elasticity for the 
$k$ leading firms) and $n$ by $k$ (the number of firms in the industry by the number of leading firms), it follows that the truncated Herfindahl index for the leading firms equals:

$$
\mathrm{H}_{\mathrm{k}}=\left(\frac{1}{\mathrm{k}}+\left[\begin{array}{c}
\mathrm{k}\left(\mu_{\mathrm{D}}-\alpha\right) \\
1-\alpha
\end{array}\right]^{2} \frac{\left.\mathrm{v}_{\mathrm{c}}{ }^{2}\right)}{\mathrm{k}} \cdot \mathrm{C}_{\mathrm{k}}{ }^{2}\right.
$$

where $v_{c}{ }^{2}$ is the coefficient of variation of marginal costs in the group of leading firms. Similarly, since competitive fringe firms are price takers, it follows that size differences will reflect efficiency differentials or not exist if technologies are similar for fringe firms, with the corresponding characteristics summarized in their supply elasticity. Accepting the last assumption, $H_{n}-k$, the H index component for the fringe firms, is easily computed and shows how $H_{n}-k$ becomes very small for high values of $\mathrm{C}_{k}$ or high numbers of fringe firms.

$$
H_{n-k}=\sum_{i=k+1}^{n} S_{i}^{2}=\frac{\left(1-C_{k}\right)^{2}}{n-k}
$$

Since $H=H_{k}+H_{n-k}$, it follows from the previous arguments that, under collusive price leadership, the $H$ dispersion within the horn for a given $C_{k}$ value can be explained by the number of leading and fringe firms in the industry, efficiency differentials and the degree of collusion amongst the leading firms. 
However, this leaves us with the problem of determining $\mathrm{C}_{k}$, the joint market share held by the dominant $k$ firms. Given the marginal cost functions and equilibrium condition (2), together with the market demand constraint, it is in principle possible to calculate the market share of each firm. Hence, concentration ratios for both the dominant group and the competitive fringe firms can be calculated and related to the set of parameters contained in these equations. However, because of the required non-linear form of the cost functions of the competitive fringe firms, the mathematics involved may become very tedious, and not always lead to clear explicit relationships. To illustrate this, we shall take here the most simple example and assume that marginal costs are proportional to output, and identical for all firms belonging to the competitive fringe: $m c_{j}=\sigma_{c} q_{j}$, $j=k+1, \ldots, n$, implying a unitary supply elasticity $(\epsilon=1)$. For convenience, we shall adopt a similar assumption for the dominant group: $m c_{i}=\sigma_{D} q_{i}, i=1, \ldots, k$. Only an efficiency difference given by the ratio of the slopes of the respective marginal cost functions $\emptyset=\sigma_{D} / \sigma_{C}$, is assumed to constitute the difference between the two groups. In addition to its analytical tractability this simple model with cost equality among the leading firms has the advantage to characterize the most favourable cost condition for collusive price leadership as discussed in the previous section. 
This quality of the model enhances the significance of the results which will be obtained hereafter.

Under the assumptions made, relations (1) and(2) lead to:

$$
\begin{gathered}
\lambda_{i}=\frac{p_{i}-m C_{i}}{p_{i}}=1-\frac{\sigma q_{i}}{\sigma q_{j}}=\frac{\alpha C_{k}+(1-\alpha) s_{i}}{\mu+\left(1-C_{k}\right)} \\
i=1, \ldots, k \quad j=k+1, \ldots, n
\end{gathered}
$$

Summing $\lambda_{i}$ over all dominant firms yields:

$$
\sum_{i=1}^{k} \lambda_{i}=k-(n-k) . \varnothing \cdot \frac{C_{k}}{1-C_{k}}=\frac{[k \alpha+(1-\alpha)] C_{k}}{\mu+\left(1-C_{k}\right)}
$$

Equality (9) is a good illustration of how (marginal) cost disadvantage variables between groups of firms are related to industry price cost margins. In the model this cost disadvantage ratio plays a crucial role for the existence of the dominant group. The continuous efforts of dominant firms to create and to take advantage of these differentials coupled to the problem of enforcing collusion and sharing benefits with all members of the industry serves as background for the model presented here (see in this connection the various arguments about dominant firm behaviour offered by Geroski and Jacquemin (1984)).

Subtracting the members of the last equality in (9) from each other we obtain an implicit function $F\left(C_{k}, k, n, \varnothing\right)$ from which $\mathrm{C}_{k}$ can be solved. (With cost equality within both 
groups of firms, $H_{k}$ equals $C_{k}{ }^{2} / k$ and $\left.H_{n-k}=\left(1-C_{k}\right)^{2} /(n-k)\right)$. From this implicit function follows that $C_{k}$ varies in the same way as (i) the degree of efficiency attained by the dominant firms versus fringe firms (inversely measured by $\varnothing$ ) (ii) the number of dominant firms; it varies inversely with (i) the degree of implicit collusion, (ii) the number of (fringe) firms. These effects follow from the following differentiations of (9):

Defining $\mathrm{F}^{\prime} \mathrm{Ck}=\frac{\delta \mathrm{F}}{\delta \mathrm{C}_{\mathrm{k}}}=$

$$
-(n-k) . \varnothing \cdot \frac{1}{\left(1-C_{k}\right)^{2}}-\frac{(\mu+1)}{\left[\mu+\left(1-C_{k}\right)\right]^{2}} \cdot[k \alpha+(1-\alpha)]<0
$$

it follows:

$$
\begin{aligned}
& \frac{\delta C_{k}}{\delta \varnothing}=\frac{(n-k) \frac{C_{k}}{1-C_{k}}}{F^{\prime} C_{k}}<0 \\
& \frac{\delta C_{k}}{\delta k}=\frac{-1+\frac{\alpha C_{k}}{\mu+\left(1-C_{k}\right)}}{F^{\prime} C_{k}}>0 \text { if }(\alpha+1) C_{k}<\mu+1 \\
& \frac{\delta C_{k}}{\delta n}=\frac{\varnothing \frac{C_{k}}{1-C_{k}}}{F^{\prime} C_{k}}<0 \\
& \frac{\delta C_{k}}{\delta \alpha}=\frac{(k-1) C_{k}}{\mu+\left(1-C_{k}\right)}<0
\end{aligned}
$$

For the aim of this paper, the interesting result of the derivations is the negative effect of $\alpha$ on the concentration of the $k$ largest firms in (13). It implies: the more 
perfect collusion is, the smaller will be market share held by the dominant firms in the industry. From equation (13) it follows (given some broad assumptions about other parameters) that the effect on $C_{k}$ of increased collusive behaviour will be larger the greater $\dot{k}$, the number of leading firms.

However, to evaluate this latter effect in connection with industry profitability, it should be verified how increasing k values change $C_{k}$, the concentration ratio and $H_{k}$, the corresponding (minimum) Hirschman-Herfindahl index ( $\mathrm{Hk}=$ $\left.\mathrm{C}_{\mathrm{k}} 2 / \mathrm{k}\right)$. It may be inspected that for low values of $\alpha$, according to the sign condition in formula (1l) these effects do increase potential collusion benefits. The effects of enlarging $k$, the number of leading firms included in the concentration ratio, for the shape of the horn is illustrated in Figure 2. The values of the truncated $\mathrm{H}_{k}$ index corresponding to the "equal cost" example coincide with the lower boundary of the horn, which shift downwards for larger $k$ values. Thus, for all given $C_{k}$ values and with $\alpha$ equal to zero, the profit collusion potential is larger, the larger is $\mathrm{k}$, the number of leading companies.

A further illustration of these effects can be obtained from numerically solving formula (9) for different values of $k$ 
FIgURE 2 : ILLUSTRATIVE MODEL WITH INCREASING COLLUSiON

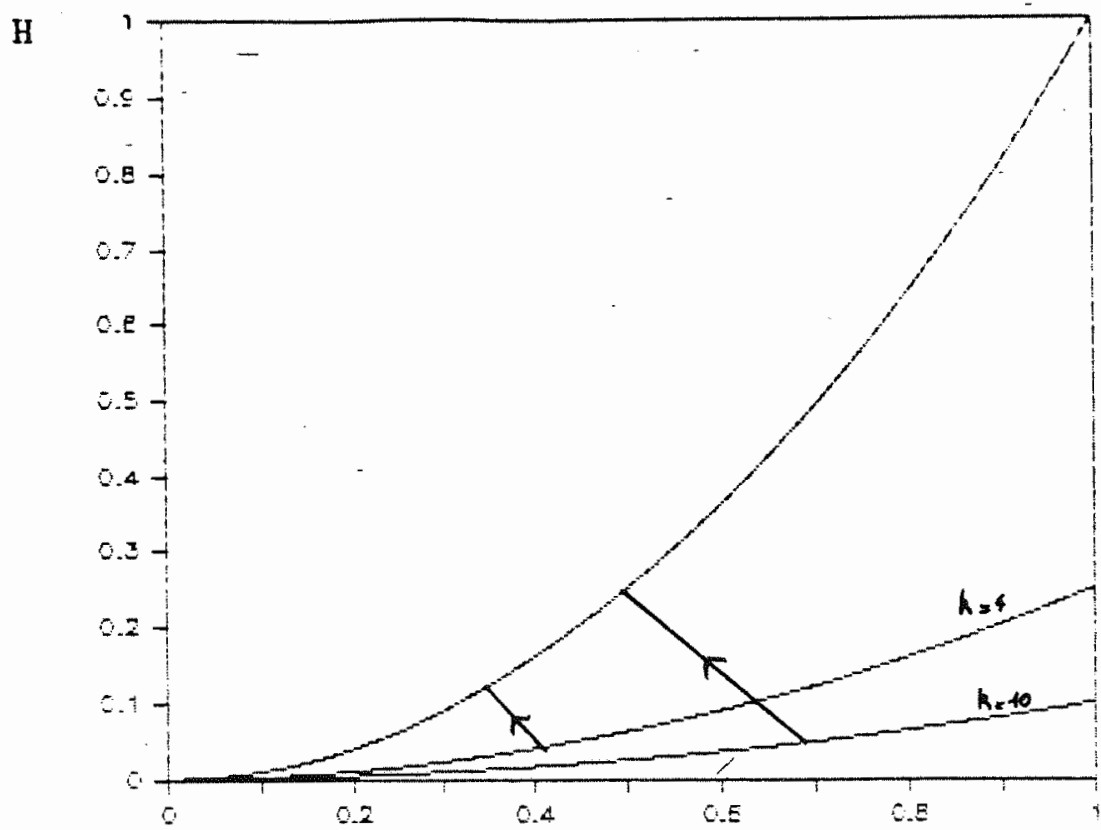

$\mathrm{C}_{4}$

and $\alpha$. This yields the following illustrative results for increasing collusion with different numbers of leading firms. The concentration effects are indicated by arrows in Figure 2 while full results are reported in Table 1.

TABLE 1. NUMERICAL RESULTS FOR THE ILLUSTRATIVE MODEL

\begin{tabular}{lllllll}
\multicolumn{1}{c}{} & \multicolumn{2}{c}{$\lambda_{\mathrm{i}}$} & \multicolumn{2}{c}{$\mathrm{H}_{\mathrm{k}}$} \\
\hline$\alpha=0$ & $\mathrm{k}=4$ & $\mathrm{k}=10$ & $\mathrm{k}=4$ & $\mathrm{k}=10$ & $\mathrm{k}=4$ & $\mathrm{k}=10$ \\
$\alpha=0.5$ & .246 & .113 & .405 & .689 & .041 & .047 \\
$\alpha=1$ & .347 & .611 & .344 & .493 & .030 & .024 \\
\hline
\end{tabular}

(Other parameters values were $\mu=0.30, \mathrm{n}=30, \varnothing=0.20$ ) 
From Table 1 we may inspect that the gains from collusion are highest for the group with ten leading firms which show the highest increase in individual price-cost margins but also the steepest decrease in concentration. These movements are reflected in both the length and inclination of the arrows drawn in Figure 2 .

\section{Summary and Conclusion}

The present paper analyzed the effects of going from noncooperative Cournot behaviour to collusive behaviour within a group of leading firms in an industry that also includes a fringe of firms acting as price takers. The study confirmed the relevance of Jesse Markham's collusion conditions by formally showing how differences in industry profit margins under collusion versus cournot behaviour increase following the height of the concentration ratio of the $k$ leading firms and the similarity of their cost curves. These differences were analyzed within the framework of an existing horn shaped relationship between the concentration ratio and the Hirschman-Herfindahl index. As potential gains from collusion, the industry profit margin differences were interpreted to constitute the strongtest incentives for dominant firms to collude. By linking up the results with the concept of a critical concentration ratio, the analysis 
was able to give some more contents to the latter concept. Finally, it was shown how increasing collusive behaviour within the group of leading firms leads to lower concentration ratios in the industry.

The analysis clearly pointed out the theoretical relevance of considering more than just one concentration measure in assessing industry performance. It would be interesting to know the empirical consequences of this theoretical observation. This research would undoubtedly yield some useful results for anti-trust policy. In the merger guidelines recently issued by the U.S. Department of Justice the choice of concentration measure as preliminary indicator of market power showed up as an important matter. 
6. References

Adelman, M.A., 1969, Comment on the 'H' Concentration Measure as a Numbers Equivalent, Review of Economics and Statistics, 51, 99-101.

d'Aspremont, C., A. Jacquemin, J. Gabszewicz, and J. Weymark, 1983, On the Stability of Collusive Price Leadership, Canadian Journal of Economics, 16, 17-25.

Boyer, M. and M. Moreaux, 1983, Distribution des rôles et espaces des stratégies dans la thérie du duopole de Stackelberg, Cahier 8333, Universite de Montréal.

Clarke, R. and S.W. Davies, 1982, Market Structure and Price Cost Margins, Economica, 49, 277-287.

Clarke, R., Davies, S. and Waterson, M., The ProfitabilityConcentration relation : Market Power or Efficiency?, Journal of Industrial Economics, 32, 435-450.

Cubbin, J., 1983, Apparent Collusion and Conjectural Variations in Differentiated oligopoly, International Journal of Industrial Organisation, 1, 155-163.

Dickson, V.A., 1981, Conjectural Variation Elasticities and Concentration, Economic Letters, 281-285.

Donsimoni, M.-P., P. Geroski and A. Jacquemin, 1984, Concentration Indices and Market Power : Two Views, Journal of Industrial Economics, $32,429-434$.

Donsimoni, M. $-\mathrm{P}$. and Mcleod B., Stable Leadership, Paper. presented at the Eleventh Annual Conference, E.A.R.I.E., Fontainebleau, vol. III, 93-108.

Encaoua, D. and A. Jacquemin, 1980, Degree of Monopoly, Indices of Concentration and Threat of Entry, International Economic Review, 21, 87-106.

Geroski, P.A., 1983, Some Reflections on the Theory and Application of Concentration Indices, International Journal of Industrial Organization, $1,79-94$.

Geroski, P.A. and A. Jacquemin, 1984, Dominant Firms and Their Alleged Decline, International Journal of Industrial Organization, $2,1-28$.

Hausse, J., 1977, The Measurement of Concentrated Industrial Structure and the Size Distribution of Firms, Annals of Economic and Social Measurement, 6, 73-107. 
Lanzillotti, R.F., 1957, Competitive Price Leadership : A Critique of Price Leadership Models, Review of Economics and Statistics, $39,56-64$.

Markham, J., 1951, The Nature and Significance of Price Leadership, American Economic Review, 41, 891-905.

Oxtenfeldt, A., 1952, Professor Markham on Price Leadership, American Economic Review, 42, 380-384.

Saving, T., 1970, Concenrtation Ratios and the Degree of Monopoly, International Economic Review, ll, 139-145.

Sleuwaegen, L., 1983, Multinational Enterprises, Industrial Concentration and the Degree of Monopoly, Paper presented at the loth EARIE Conference, August 23-25, Bergen, Norway.

Sleuwaegen, L. and $w$. Dehandschutter, 1985, The Critical Choice Between the Concentration Ratio and the H-Index in Assessing Industry Performance, Onderzoeksrapport 8505 , University of Louvain.

Stigler, G.J., 1964, A Theory of Oligopoly, Journal of Political Economy, 62, $1,44-61$. 